\title{
Early time-locked gamma response and gender specificity
}

\author{
Sirel Karakaş a,b,*, İlhan Tüfekçi ${ }^{c}$, Belma Bekçi ${ }^{\mathrm{a}, \mathrm{b}}$, Emine D. Çakmak ${ }^{\mathrm{a}, \mathrm{b}}$, \\ Elvin Doğutepe ${ }^{a, b}$, Ö. Utku Erzengin ${ }^{a, b}$, Arzu Özkan ${ }^{a, b}$, Orhan Arıkan ${ }^{c}$ \\ ${ }^{a}$ Hacettepe University, Department of Experimental Psychology, Beytepe Campus 06532, Ankara, Turkey \\ ${ }^{\mathrm{b}}$ TÜBITAK Brain Dynamics Multidisciplinary Research Network, Ankara, Turkey \\ ${ }^{\mathrm{c}}$ Bilkent University, Department of Electrical Engineering, 06533 Bilkent, Ankara, Turkey
}

Received 28 December 2004; received in revised form 1 May 2005; accepted 24 May 2005 Available online 16 August 2005

\begin{abstract}
The aim was to investigate whether gender is a causative factor in the gamma status according to which some individuals respond with time-locked, early gamma response, $\mathrm{G}+$, while the others do not show this response, $\mathrm{G}-$. The sample consisted of 42 volunteer participants (between 19 and 37 years of age with at least 9 years of education). There were 22 females and 20 males. Data were collected under the oddball paradigm. Auditory stimulation $(10 \mathrm{~ms}$ r/f time, $50 \mathrm{~ms}$ duration, $65 \mathrm{~dB}$ SPL) consisted of target $(2000 \mathrm{~Hz} ; p=.20)$ stimuli that occurred randomly within a series of standard stimuli $(1000 \mathrm{~Hz} ; p=.80)$. Gamma responses were studied in the amplitude frequency characteristics, in the digitally filtered event-related potentials (f-ERPs) and in the distributions which were obtained using the recently developed time-frequency component analysis (TFCA) technique. Participants were classified into G+ and G- groups with a criterion of full agreement between the results of an automated gamma detection technique and expert opinion. The $2 \times 2 \times 2$ ANOVA on f-ERPs and $2 \times 2 \times 2$ multivariate ANOVA on TFCA distributions showed the main effect of gamma status and gender as significant, and the interaction between gamma status and gender as nonsignificant. Accordingly, individual difference in gamma status is a reliable phenomenon, but this does not depend on gender. There are conflicting findings in the literature concerning the effect of gender on ERP components (N100, P300). The present study showed that if the gamma status is not included in research designs, it may produce a confounding effect on ERP parameters.
\end{abstract}

(C) 2005 Elsevier B.V. All rights reserved.

Keywords: Gamma response; Gender; Individual differences; Event-related potentials; Event-related oscillations; Time-frequency analysis

\section{Introduction}

The study of oscillatory responses in brain's neuroelectric activity proved useful in understanding the way brain processes information (Adrian, 1942; for review, see Başar, 1976, 1980, 1998, 1999; Berger, 1929). Among the various oscillatory responses, the gamma response of the brain has received considerable attention. Existing literature includes a fair amount of knowledge about the gamma response for which the lowermost value was found to be 25

\footnotetext{
* Corresponding author. Hacettepe University, Department of Experimental Psychology, Beytepe Campus 06532, Ankara, Turkey. Tel.: +90 312 2978335; fax: +90 3122992100 .

E-mail address: skarakas@hacettepe.edu.tr (S. Karakaş).
}

$\mathrm{Hz}$ and the uppermost value $70 \mathrm{~Hz}$ (for review, see BaşarEroğlu et al., 1996; Galambos, 1992; Gurtubay et al., 2001; Karakaş et al., 2001). There are basically two types of eventrelated gamma responses and these are discriminated on the basis of temporal localization and time-locking (Gurtubay et al., 2001; Başar-Eroğlu et al., 1996; Karakaş et al., 2001). The "late" gamma occurs in the $130-400$ ms poststimulus time window and has an induced character. The "early" gamma response occurs within the $150 \mathrm{~ms}$ poststimulus window from mainly the frontocentral recording sites and is time-locked to the stimulus.

The early, time-locked gamma response is mainly related to the earlier operations of information processing that culminate in sensation and perception (Gurtubay et al., 2001; Karakaş et al., 2001; Karakaş and Başar, 1998, 
2004). However, in spite of its early occurrence, individual differences were reported in this time-locked gamma response such that some individuals showed time-locked gamma response, $\mathrm{G}^{+}$, and others did not, $\mathrm{G}-$. Furthermore, these differences were found to be related to the higher cognitive processes such as learning, memory and executive functions (Jokeit and Makeig, 1994; Karakaş et al., 2003).

Cognitive processes are differentially affected with gender such that there is generally a female superiority in verbal functions and a male superiority in visuo-spatial functions (Kolb and Whishaw, 1996; Maccoby and Jacklin, 1974). Gender effect has also been studied on one type of event-related activity of the brain, the event-related potentials (ERPs). The N200 component (N2a/mismatch negativity and $\mathrm{N} 2 \mathrm{~b}$ ) is related to varying degrees of attention, from preattention/passive attention to focused attention/active attention (Karakaş et al., 2000a,b; Naatanen, 1990, 1992; Naatanen and Picton, 1986). Some studies reported that N200 is higher in amplitude in males (Gölgeli et al., 1999; Nagy et al., 2003). However, other studies failed to find such an effect, or conversely, found that this ERP component was higher in amplitude in females (Barrett and Fulfs, 1998; Hoffman and Polich, 1999; Kasai et al., 2002). In females, the amplitude of the P300 (P3b) was found to be higher (Orozco and Ehlers, 1998; Osterhout et al., 1997; Hoffman and Polich, 1999). Such findings suggested that there was a gender effect on attention allocation and memory updating processes which are related to P300 (Sutton et al., 1965; Polich and Kok, 1995).

The ERP studies suggest gender as a causative factor for the presence of the gamma response. To our knowledge, this issue has not been studied in the relevant literature. The aim of the present study was to study the effect of gender on the gamma response and, using techniques of time-domain, frequency-domain and time-frequency domain analysis, to test the hypothesis that individual differences in this response are due to gender.

\section{Methods}

\subsection{Participants}

The sample was obtained from a total of 58 volunteers who met the below specified inclusion and exclusion criteria. These participants were classified into $\mathrm{G}^{+}$and $\mathrm{G}-$ groups. The sample consisted of 42 volunteer participants with respect to whom the automated gamma detection technique and expert opinion showed 100\% agreement with regards to gamma status $(\mathrm{G}+$ or $\mathrm{G}-$ ).

There were 20 males and 22 females in the sample. Participants were young adults between 19 and 37 years of age and they had at least 9 years of education. Participants were naive to electrophysiological studies. All were right- handed. Volunteering participants gave informed consent to participate in the study after the purpose and nature of the experiment were fully explained.

The sample included only those individuals who reported being free of neurological or psychiatric problems. Individuals who were, at the time of testing, under medication that could affect cognitive processes or who stopped taking such medication were excluded. The hearing level of the potential subjects was assessed through computerized audiometric testing prior to the experimental procedures. Individuals with hearing deficits were not included in the study.

\subsection{Stimulation and response parameters}

The auditory stimuli had $10 \mathrm{~ms} \mathrm{r} / \mathrm{f}$ time, $50 \mathrm{~ms}$ duration and were presented over the headphones at 65 $\mathrm{dB}$ SPL. Two types of stimuli were used: the standard and the deviant. The standard stimuli $(n=120-130)$ were $1000 \mathrm{~Hz}$. Deviant stimuli ( $=30-33)$ were $2000 \mathrm{~Hz}$. The deviant stimuli occurred randomly with a probability of about 0.20 within a series of standard stimuli that were presented with a probability of about 0.80 . According to the procedures of the oddball paradigm $(\mathrm{OB})$, participants had to mentally count the occurrence of deviant (target) stimuli and to report them after the session was terminated (for details of the methodology, see Karakaş et al., 2000a).

\subsection{Electrophysiological procedures}

Electrical activity of the brain, the prestimulus electroencephalogram (EEG) and the poststimulus ERP, were recorded in an electrically shielded, sound-proof chamber. Recordings were taken from 15 recording sites (reference: linked earlobes; ground: forehead) of the 10 20 system under eyes-open condition using a commercial electrode cap (Electro-Cap) of appropriate size. The present study reports findings from the midline recording sites $(\mathrm{Fz}, \mathrm{Cz}, \mathrm{Pz})$.

Bipolar recordings were made of electroocular and electromyographic activity for online rejection of responses whose amplitudes exceeded $\pm 50 \mu \mathrm{V}$ and offline rejection of artifacts by means of visual inspection. Electrooculogram (EOG) was recorded between the outer canthus and supraorbital area of the left eye. Electromyogram (EMG) was recorded between two electrodes that were placed at the submental area. Rejection occurred for epochs that contained gross muscular activity, eye movements or blinks. Electrical activity was amplified and filtered with a bandpass between 0.16 and $70 \mathrm{~Hz}(3 \mathrm{~dB}$ down, $12 \mathrm{~dB} /$ octave). It was recorded with a sampling rate of $500 \mathrm{~Hz}$ and a total recording time of $2048 \mathrm{~ms}, 1024 \mathrm{~ms}$ of which served as the prestimulus baseline. EEG-ERP data acquisition, analysis, and storage were achieved by a commercial system (Brain Data 2.92). 


\subsection{Data analysis}

\subsubsection{Time-domain analysis}

Selective averaging of ERPs was used for obtaining representative waveforms for the experimental conditions and also for separating the ERP (evoked activity) from the EEG (spontaneous activity) (Dawson, 1954).

\subsubsection{Frequency-domain analysis}

The frequency responses of brain's neuroelectricity were calculated through two techniques: transient response frequency characteristics (TRFC) and digital filtering (DF).

The amplitude frequency characteristics (AFCs) were computed using the TRFC method (Başar, 1980). This method computes the AFCs, $|G(j \omega)|$, by the application of Laplace transform (i.e., one-sided Fourier transform) to the unfiltered transient (evoked) response, $c(t)$, of the system (Başar, 1998; Brandt and Jansen, 1991; Jervis et al., 1983; Kolev and Yordanova, 1997; Parvin et al., 1980; Röschke et al., 1995, 1996; Röschke and Aldenhoff, 1991; Solodovnikov, 1960). The AFC is expressed in relative units and it reflects the amplification in the studied frequency channels. The presence of peaks in the $\mathrm{AFC}$ thus reveals the frequency selectivities of the system and these are interpreted as the most preferred oscillations when responding to stimuli (for details of methodology, see Karakaş and Başar, 1998). The AFCs were used in the present study for a global and simultaneous description of selectivities in the studied frequency range $(1-100 \mathrm{~Hz})$. The technique was also used for determining the limits of the resonant selectivities that appeared as maxima in the AFCs. These values were used for determining the frequency cutoff values of the digital filters.

In DF, the experimentally obtained transient (evoked) response, $c(t)$, is theoretically filtered by means of the convolution integral using the weighting function, $g_{\mathrm{KF}}(t)$, of adequately determined ideal filter (for details of methodology, see Cook and Miller, 1992; Farwell et al., 1993; Karakaş and Başar, 1998; Ungan and Başar, 1976). Digital filtering produces visual displays of the time courses of oscillatory components within the frequency limits of the utilized filters. Digital filtering thus displays the oscillatory activity of different frequency bands over the studied time interval $(-1024 \mathrm{~ms}$ to $+1024 \mathrm{~ms})$. In the present study, digital passband filtering was responseadaptive; filter limits were determined from selectivity channels that were displayed in the AFCs as distinct peaks. In other words, the bandwidth values of the digital filters that were chosen coincided with the limits of the resonant selectivities that were displayed in the AFC of each condition. It was found that $28-46 \mathrm{~Hz}$ frequency limits described the gamma range in the different experimental conditions of the present study (also see Karakaş et al., 2001; Karakaş and Başar, 1998).

\subsubsection{Time-frequency domain analysis}

As the above explanations show, ERPs basically represent the analysis of brain electrical responses in the timedomain. Fourier transform and the AFCs represent the frequency components in the signal in the frequency domain. Digital filtering is based on the findings of AFC and displays the progression of oscillations of those frequency ranges that are determined from the AFCs. Both techniques of frequency analysis assume that the studied system is linear and stationary.

The localization of signals simultaneously in the time and frequency planes can be achieved using Short-Time Fourier Transform (STFT). However, when ERP components are closely localized in the time-frequency plane, STFT may not be adequate to resolve them (Cohen, 1989, 1995). Wigner distribution significantly improves the resolution of the individual ERP components. The Wigner distribution $W_{x}(t, f)$ of a signal $x(t)$ is defined as

$W_{x}(t, f)=\int_{-\infty}^{\infty} x(t+\tau / 2) x^{*}(t-\tau / 2) \mathrm{e}^{-j 2 \pi f \tau} \mathrm{d} \tau$.

As it is seen from the definition, Wigner distribution is a bilinear representation. Therefore, Wigner distribution of multi-component signals or mono-component signals with curved time-frequency supports will be cluttered by spurious terms called cross-terms. The existence of crossterms may decrease the interpretability of the timefrequency distribution. ERPs, like other non-stationary signals, require an analysis technique that is free from cross-terms and that also render a high-resolution timefrequency distribution.

The simultaneous localization of the gamma component in the time and frequency domains was achieved in the present study using the recently developed time-frequency component analysis (TFCA) technique (Arrkan et al., 2003; Özdemir et al., 2001, 2005; Özdemir and Arıkan, 2000, 2001). Fig. 1 presents a flow diagram of the algorithm that was used in TFCA. The basic aim of this algorithm was as follows: Given a multi-component sampled signal $x\left(n / \Delta_{x}\right)$, $-N / 2 \leq n \leq N / 2-1$, to extract its components and to compute its time-frequency distribution. It is assumed that $x(t)$ is scaled before its sampling so that its Wigner distribution is inside a circle of a diameter $\Delta_{x} \leq \sqrt{N}$ (see Ozaktas et al., 1996).

The steps of the algorithm for TFCA are given below.

1. Initialize the residual signal and the iteration number as $r^{0}(t):=x(t), i:=1$, respectively.

2. Identify the time-frequency support of the component $s_{i}(t)$ using the watershed segmentation algorithm (Vincent and Soille, 1991). After manually determining the appropriate rotation angle $\phi_{i}$ and the fractional domain $a_{i}=2 \phi_{i} / \pi$, estimate the spine $\psi_{i, a_{i}}(t)$ of the fractional Fourier transform $r_{a_{i}}^{i-1}(t)$ using an instantaneous frequency estimation algorithm. Then determine the amount of the required frequency shift $\delta_{f_{i}}$ on the spine $\psi_{i, a_{i}}(t)$. 


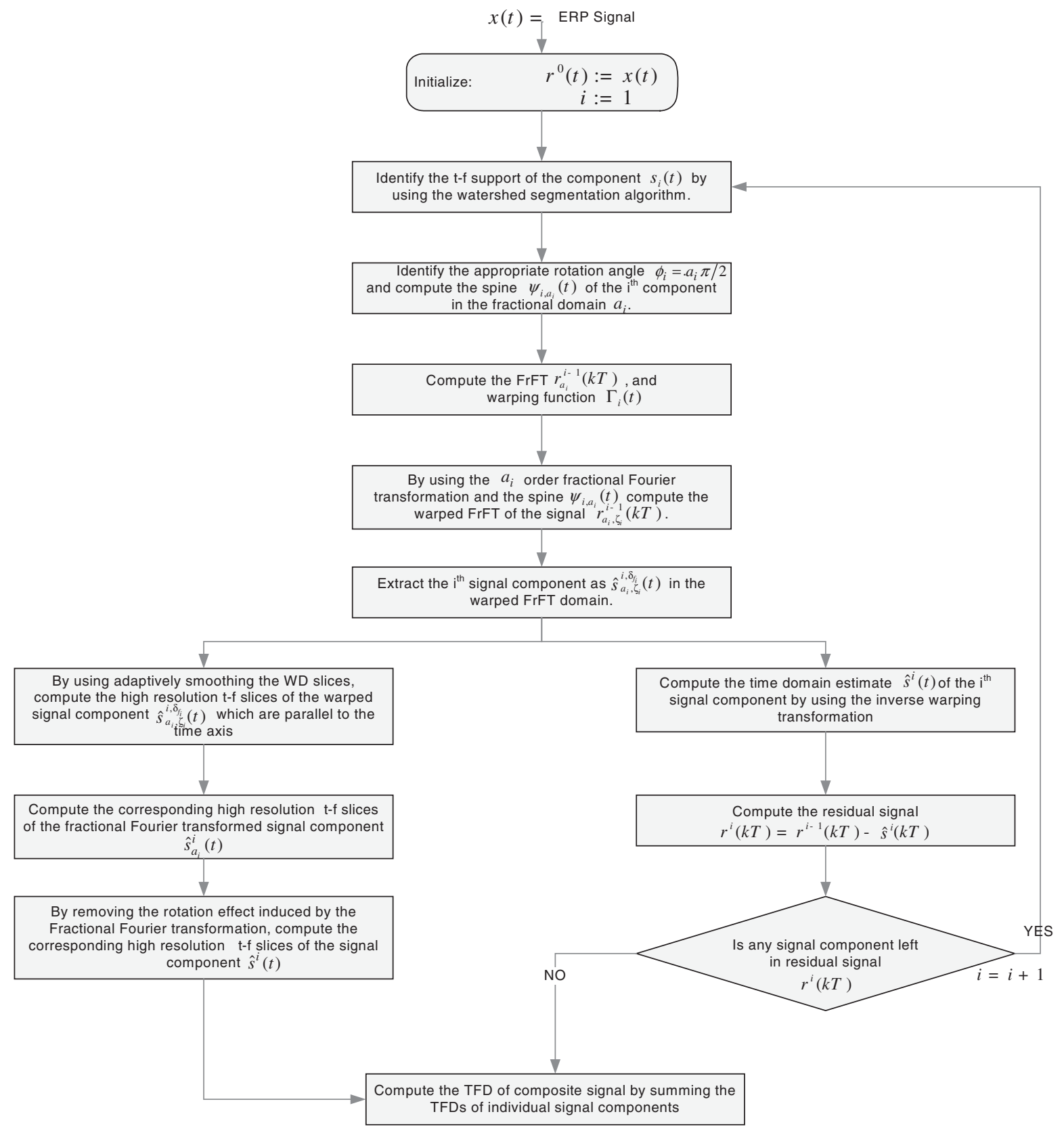

Fig. 1. Detailed flow diagram of time-frequency component analyzer (TFCA).

3. Compute the sampled FrFT $r_{a_{i}}^{i-1}(k T), a_{i}=2 \phi_{i} / \pi$, from $r^{i-1}(k T)$ using the fast fractional Fourier transform algorithm (see Ozaktas et al., 1996).

4. Define the warping function $\zeta_{i}(t)=\Gamma_{i}^{-1}\left(f_{\psi_{i}}\left(t-t_{1}\right)\right)$, where $\Gamma_{i}(t)=\int_{t_{1}}^{t}\left[\psi_{a_{i}}\left(t^{\prime}\right)+\delta_{f_{i}}\right] \mathrm{d} t^{\prime}$ and $f_{\psi_{i}}=\Gamma_{i}\left(t_{N}\right) /\left(t_{N}-t_{1}\right)$. Compute the sampled warping function $\zeta_{i}(k T)$.

5. Compute the sampled warped signal $r_{a_{i}, \zeta_{i}}^{i-1}(k T)$ as

$r_{a_{i}}^{i-1, \delta_{f_{i}}}(k T)=\mathrm{e}^{j 2 \pi \delta_{f_{i}} k T} r_{a_{i}}^{i-1}(k T)$

$r_{a_{i}, \zeta_{i}}^{i-1, \delta_{f_{i}}}(k T)=\mathrm{e}^{-j 2 \pi \delta_{f_{i}} k T} r_{a_{i}}^{i-1, \delta_{f_{i}}}\left(\zeta_{i}(k T)\right)$
6. Estimate the $i$ th component by incision of the timefrequency domain as

$\hat{s}_{a, \zeta_{i}}^{i, \delta_{f_{i}}}(t)=h_{2}(t)\left[h_{1}(t) * r_{a_{i}, \zeta_{i}}^{i-1, \delta_{f_{i}}}(t)\right]$,

where $h_{2}(t)$ is a time-domain mask and $h_{1}(t)$ is the inverse Fourier transform of a frequency-domain mask $H_{1}(f)$.

7. For each TFD slice of $s^{i}(t)$, compute $y_{a_{i}, \zeta_{i}}(k T)=$ $\hat{s}_{a_{i}, \zeta_{j}}^{i, \delta_{f_{i}}}(k T) \mathrm{e}^{j 2 \pi \Delta_{\psi} \zeta_{i}(k T)}$, after choosing the slice offset $\Delta_{\psi}$.

8. Compute the sampled TFD $\mathbb{T} \mathbb{F}_{y_{a_{i}}, \zeta_{i}}\left(m \bar{T}, f_{\psi_{i}}\right), t_{1} / \bar{T} \leq m$ $\leq t_{N} / \bar{T}$ of $y_{a_{i}, \zeta_{i}}(t)$ using the directional smoothing algorithm 
(cf. Özdemir and Arıkan, 2000), where $\bar{T}$ is the sampling interval of the TFD slice.

9. The TFD slice of $s^{i}(t)$ is given by

$\mathbb{T} \mathbb{F}_{s^{i}}\left(t_{r}(m \bar{T}), f_{r}(m \bar{T})\right)=T F_{y_{a_{i}, \zeta_{i}}}\left(m \bar{T}, f_{\psi_{i}}\right)$,

where $\left(t_{r}(m \bar{T}), f_{r}(m \bar{T})\right)$ define a curve in the time-frequency plane parameterized by the variable $m \bar{T}$ :

$$
\begin{aligned}
& t_{r}(m \bar{T})= \zeta(m \bar{T}) \cos \left(\frac{a_{i} \pi}{2}\right) \\
&-\left(\psi(\zeta(m \bar{T}))+\Delta_{\psi}\right) \sin \left(\frac{a_{i} \pi}{2}\right) \\
& f_{r}(m \bar{T})= \zeta(m \bar{T}) \sin \left(\frac{a_{i} \pi}{2}\right) \\
&+\left(\psi(\zeta(m \bar{T}))+\Delta_{\psi}\right) \cos \left(\frac{a_{i} \pi}{2}\right), \\
& t_{1} / \bar{T} \leq m \leq t_{N} / \bar{T} .
\end{aligned}
$$

10. Estimate the sampled $s^{i}(t)$ by taking the inverse of the warping, frequency modulation and the fractional Fourier transformation on the sampled $\hat{\mathrm{s}}_{a_{i} \zeta_{\zeta_{i}}}^{\delta_{\zeta_{i}}}(t)$

$\hat{s}_{a_{i}}^{i, \delta_{f_{i}}}(k T)=\mathrm{e}^{j 2 \pi \delta_{f_{i}} \zeta_{i}^{-1}(k T)} \hat{s}_{a_{i}, \zeta_{i}}^{i, \delta_{f_{i}}}\left(\zeta_{i}^{-1}(k T)\right)$,

$\hat{s}_{a_{i}}^{i}(k T)=\mathrm{e}^{-j 2 \pi \delta_{f_{i}} k T} \hat{s}_{a_{i}}^{i, \delta_{f_{i}}}(k T)$,

$\hat{s}^{i}(k T)=\left\{F^{-a_{i}} \hat{s}_{a_{i}}^{i}\right\}(k T)$.

11. Compute the residual signal $r^{i}(k T)=r^{i-1}(k T)-$ $\hat{s}^{i}(k T)$.

if any signal component is left in residual signal $r^{i}(k T)$ then

Set $i=i+1$, and GOTO step 2,

else

Compute the time-frequency distribution of the composite signal as the sum of the time-frequency distributions of individual signal components.

\section{endif}

As the algorithm shows, TFCA suppresses the crossterms (both inner and outer interference terms), which are associated with the Wigner distribution. TFCA can identify the auto-terms in the time-and-frequency plane, and can do this for mono- and multi-component signals with linear or curved time-frequency supports. As such, TFCA identifies and extracts the maximal energies of the oscillatory components from the composite (multi-component) ERP signal (Özdemir et al., 2005). Accordingly, as a highresolution signal analysis technique, TFCA can produce the global distribution of uncontaminated signal components in the form of spatially and temporally integrated, time-varying oscillatory activity of various frequency ranges. The only assumption in TFCA is that signal components have non-overlapping supports in the timefrequency plane.

\subsubsection{Detection of early gamma response based on time- frequency domain characteristics}

Detection of the early gamma response $(0-150 \mathrm{~ms}$ poststimulus time window) was realized using an automated detection technique (Fig. 2).

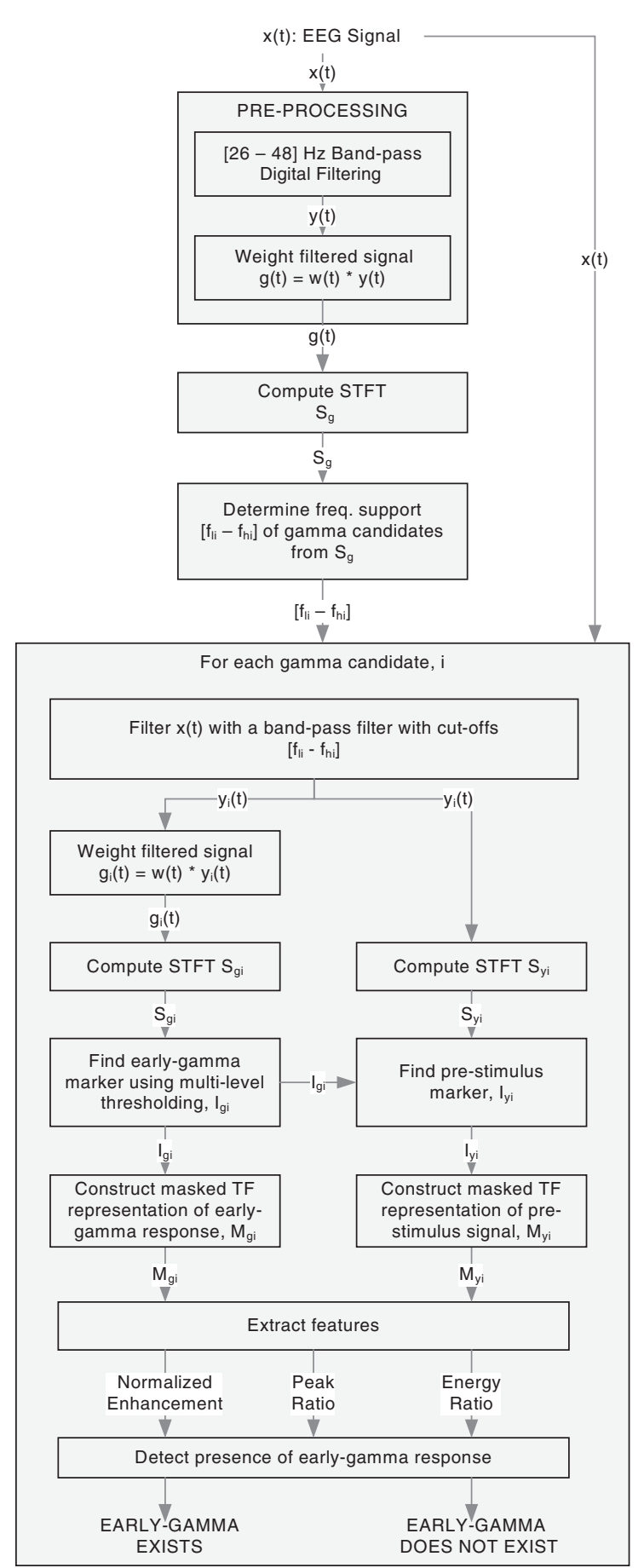

Fig. 2. Flow diagram of the detection technique for the early gamma response. 
The major steps of the detection algorithm were: (1) Preprocessing of the EEG data to enhance detection. (2) Computing Short-Time Fourier Transform (STFT) of the pre-processed signal. (3) Locating time-frequency domain peaks. (4) Identifying the frequency interval of each detected peak. (5) Filtering the EEG recording within the identified frequency intervals in Step 4. (6) Computing two STFTs. (a) STFT of the signal obtained in Step 5: $S_{y_{i}}(t, f)$; (b) STFT of the signal obtained in Step 5 after time weighting: $S_{g_{i}}(t, f)$. Here $i$ denotes the index of the potential early gamma response. (7) Extracting the support marker for $S_{g_{i}}(t, f): I_{g_{i}}(t, f)$. (8) Forming the support marker for $S_{y_{i}}(t, f)$ by using $I_{g_{i}}(t, f)$. (9) Extracting quantitative time-frequency domain features. (10) Detecting the early gamma response based on the extracted features.

As Fig. 2 shows, the detection algorithm starts with filtering the EEG signal, $x(t)$, in $(26-48) \mathrm{Hz}$ band (Karakaş and Başar, 1998) to obtain the filtered response, $y(t)$. The filter used is an infinite impulse response (IIR) filter with 14 coefficients which have $46 \mathrm{~dB}$ attenuation in stopbands, and $0.1 \mathrm{~dB}$ ripple in the passband.

The pre-processed signal $g(t)$ is obtained by multiplying the filtered EEG signal with the time-domain weighting function, $w(t)$ :

$g(t)=w(t) \times y(t)$.

The support of $w(t)$ is chosen to emphasize features in -50 to $300 \mathrm{~ms}$. The algorithm looks for early gamma response in the following STFT magnitude:

$S_{g}(t, f)=\left|\int_{-\infty}^{+\infty} g(\tau) \frac{1}{\sqrt{2 \pi} \sigma} \mathrm{e}^{\frac{-(t-\tau)^{2}}{2 \sigma^{2}}} \mathrm{e}^{-j 2 \pi f \tau} \mathrm{d} \tau\right|$.

The width parameter, $\sigma$, of the sliding STFT window is chosen as $57 \mathrm{~ms}$.

By multi-level thresholding $S_{g_{i}}(t, f)$, a compact timefrequency support of $g_{i}(t)$ is obtained. In this way, a marker $I_{g_{i}}(t, f)$ indicating the regions with high energy on the STFT magnitude is obtained. By multiplying $S_{g_{i}}(t, f)$ with $I_{g_{i}}(t, f)$, the masked time-frequency (TF) representation is obtained:

$M_{g_{i}}(t, f)=S_{g_{i}}(t, f) \times I_{g_{i}}(t, f)$.

Similarly, masked TF representation of the prestimulus response $M_{y_{i}}(t, f)$ is computed as:

$M_{y_{i}}(t, f)=S_{y_{i}}(t, f) \times I_{y_{i}}(t, f)$,

where the prestimulus marker, $I_{y_{i}}(t, f)$, is obtained by dilation of the gamma marker $I_{g_{i}}(t, f)$ within the prestimulus region boundaries.

The following set of features is chosen for robust differentiation of the pre-and poststimulus response in the presence of early gamma signal.

1. The normalized enhancement, $\gamma_{\mathrm{e}}$ :

$\gamma_{\mathrm{e}}=\frac{p_{\mathrm{g}}-\mu_{\mathrm{p}}}{\sigma_{\mathrm{p}}}$ where $p_{\mathrm{g}}$ is the peak value of $M_{g_{i}}(t, f), \mu_{\mathrm{p}}$ and $\sigma_{\mathrm{p}}$ are the mean value and standard deviation of $M_{y_{i}}(t, f)$, respectively.

2. The peak ratio, $\gamma_{\mathrm{p}}$ :

$\gamma_{\mathrm{p}}=\frac{p_{\mathrm{g}}}{p_{\mathrm{p}}}$

where $p_{\mathrm{p}}$ denotes the peak value of the masked TF representation of the prestimulus.

3 . The ratio of energies of the masked TF representations, $E_{\mathrm{r}}$ :

$E_{\mathrm{r}}=\frac{\int M_{g_{i}}(t, f)^{2} \mathrm{~d} t \mathrm{~d} f}{\int I_{g_{i}}(t, f) \mathrm{d} t \mathrm{~d} f} \times\left[\frac{\int M_{y_{i}}(t, f)^{2} \mathrm{~d} t \mathrm{~d} f}{\int I_{y_{i}}(t, f) \mathrm{d} t \mathrm{~d} f}\right]^{-1}$.

To illustrate the efficiency of the extracted features, a neural network (NN) classifier with 3 inputs corresponding to each extracted feature and a single output indicating the presence of the early gamma response was designed. The neural network had two hidden layers, with 30 and 15 neurons, respectively. The transfer functions in all of the layers were hyperbolic tangent transfer functions.

The designed neural network was trained by using a back-propagation algorithm on a set, which contained 21 signals that exhibited gamma response, $\mathrm{G}^{+}$, and 14 signals that did not exhibit gamma response, $\mathrm{G}-$. Preliminary classification of the signals into $\mathrm{G}+$ and $\mathrm{G}-$ was achieved through expert opinion. The trained network had a $95 \%$ success rate on the training data. Then the neural network classifier was tested on 102 signals, which were obtained in response to the target and standard stimuli of the oddball paradigm from the different recording sites. The expert and the classifications of this preliminary neural network coincided in $76 \%$ of the cases: $\mathrm{G}+$ concordance was $47.06 \%$ and $\mathrm{G}-$ concordance was $29.41 \%$. Among the misclassified cases, the false-positives were $7.84 \%$ and the false negatives were $15.69 \%$. This neural network has been designed for the present study and may be further refined. The expert opinion was based on digitally filtered waveforms which were, basically, time-domain representations of the oscillatory responses whose frequency limits were determined from the AFCs. Taking these into consideration, the present study analyzed those gamma responses where decision concerning the gamma status of both the expert and the neural network classifier was identical.

\section{Results}

\subsection{ERPS and time-locked gamma responses in gender subtypes}

Figs. 3 and 4 display the ERPs (first block of figures) for females $(\mathrm{F})$ and males $(\mathrm{M})$ which were obtained in response to the target and the standard stimuli, respectively, from the $\mathrm{Fz}, \mathrm{Cz}$ and $\mathrm{Pz}$ recording sites. Table 1 shows the descriptive 

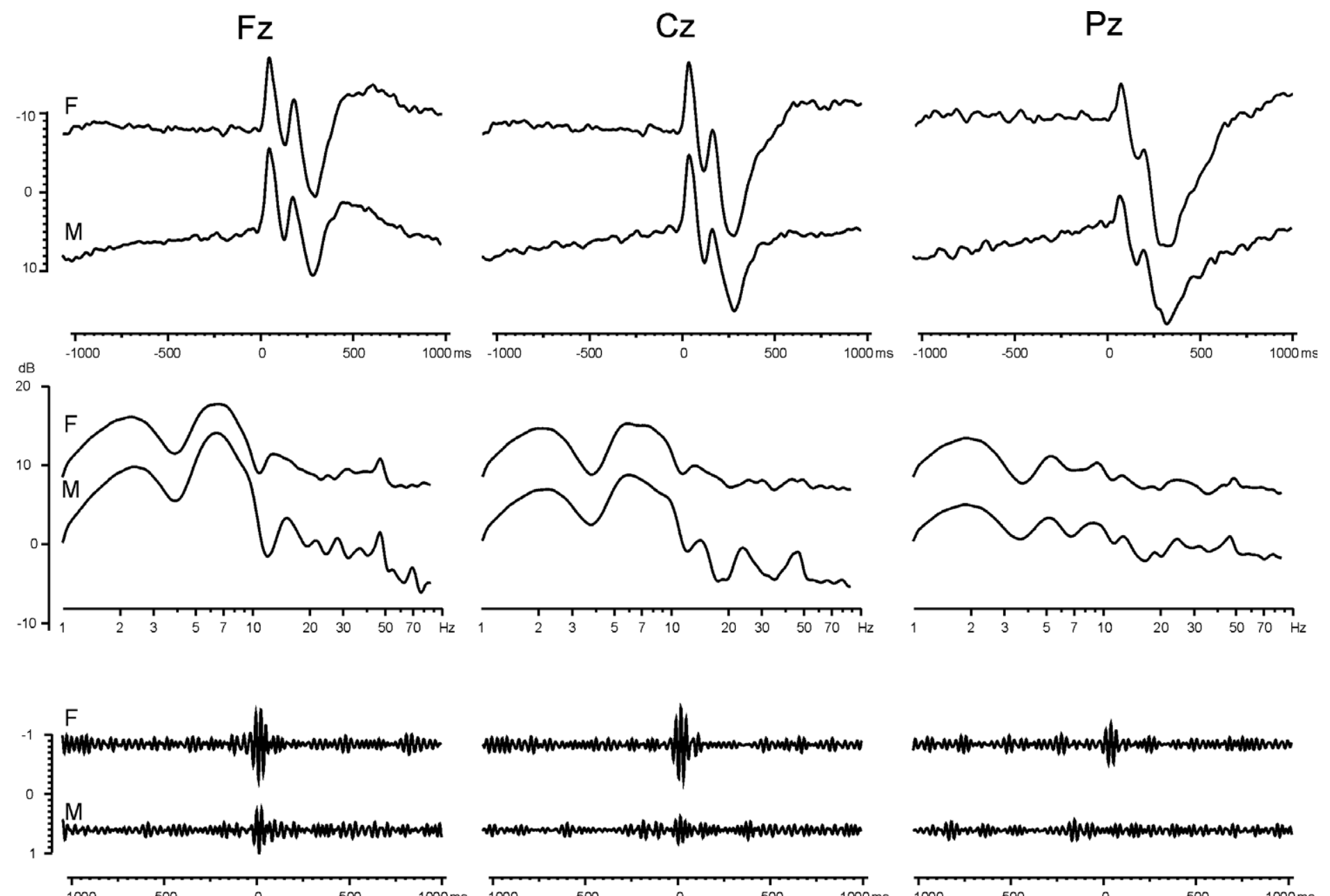

Fig. 3. Findings obtained in response to the target stimuli. First block: Event-related potential waveforms (ERPs). Second block: Amplitude frequency characteristics (AFCs). Third block: Digitally filtered waveforms (f-ERPs) for females (F: first rows in each block) and males (M: second rows in each block). Recording sites: Fz, Cz and Pz. Note that the $Y$-axis for ERPs, AFCs and f-ERPs have scales proportional to the largest amplitude values in each representation. Stimulation onset was marked with "0". 

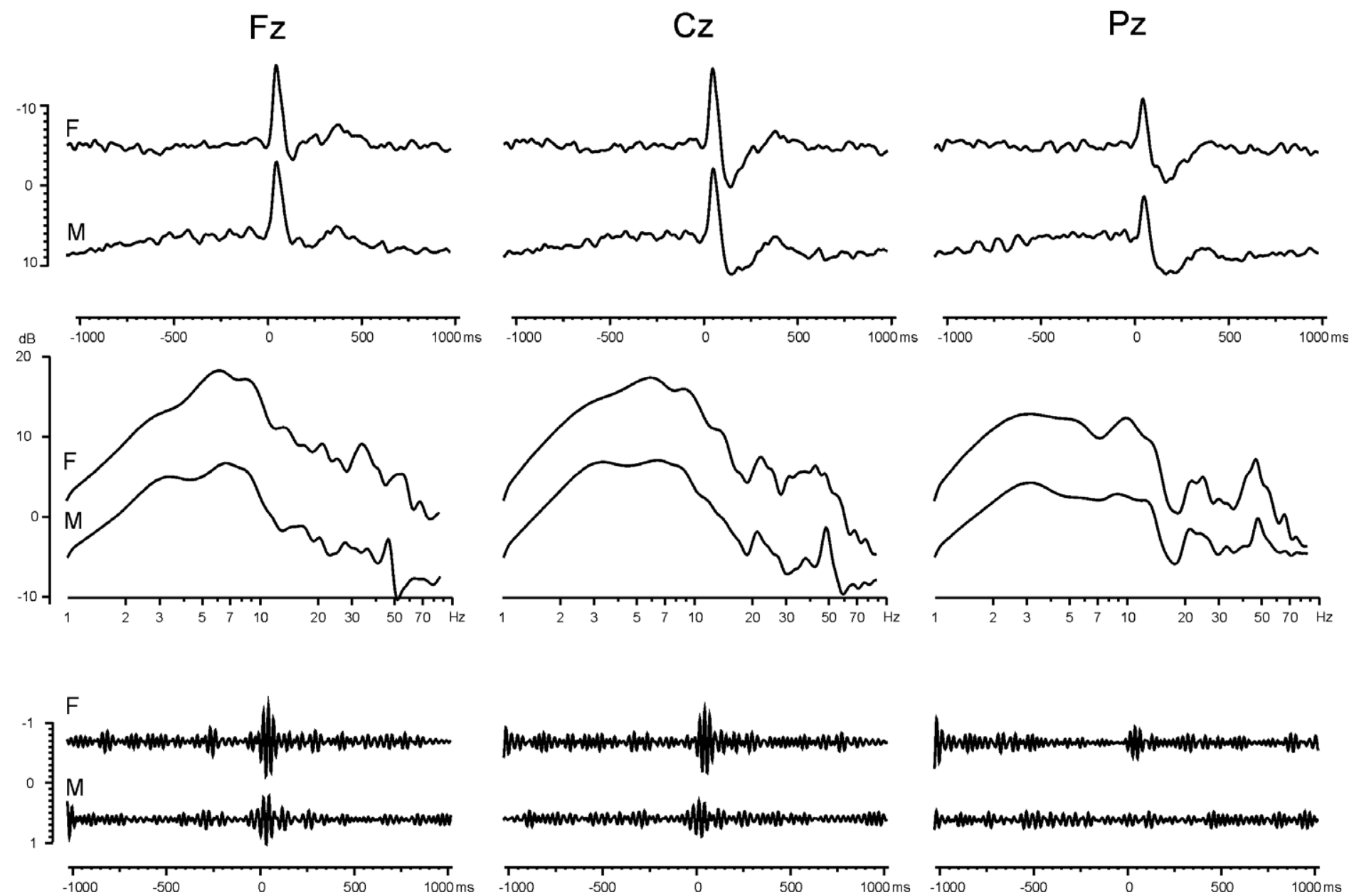

Fig. 4. Findings obtained in response to the standard stimuli. First block: The event-related potential waveforms (ERPs). Second block: Amplitude frequency characteristics (AFC). Third block: Digitally filtered waveforms (f-ERPs) for females (F: first rows in each block) and males (M: second rows in each block). Recording sites: Fz, Cz and Pz. Note that the $Y$-axis for ERPs, AFCs and f-ERPs have scales proportional to the largest amplitude values in each representation. Stimulation onset was marked with " 0 ". 
Table 1

Means and standard deviations of the amplitudes of target-elicited and standard-elicited ERP components (N100, N200, P300) according to gender (Female, Male), stimulus type (Target, Standard) and recording site ( $\mathrm{Fz}, \mathrm{Cz}$, $\mathrm{Pz})$

\begin{tabular}{|c|c|c|c|c|c|}
\hline & & & \multicolumn{3}{|l|}{ Amplitude $(\mu \mathrm{V})$} \\
\hline & & & $\mathrm{Fz}$ & $\mathrm{Cz}$ & $\mathrm{Pz}$ \\
\hline \multirow[t]{4}{*}{ N100 } & Female & Target & $-9.64( \pm 4.02)$ & $-9.02( \pm 3.60)$ & $-5.01( \pm 3.13)$ \\
\hline & & Standard & $-10.26( \pm 4.51)$ & $-9.90( \pm 4.31)$ & $-6.51( \pm 3.26)$ \\
\hline & Male & Target & $-12.52( \pm 5.08)$ & $-11.43( \pm 4.24)$ & $-6.82( \pm 3.39)$ \\
\hline & & Standard & $-9.67( \pm 4.60)$ & $-9.17( \pm 4.10)$ & $-5.95( \pm 3.36)$ \\
\hline \multirow[t]{4}{*}{ N200 } & Female & Target & $-5.39( \pm 6.07)$ & $-1.69( \pm 6.17)$ & $2.30( \pm 4.46)$ \\
\hline & & Standard & $-2.98( \pm 4.37)$ & $-0.08( \pm 4.50)$ & $0.93( \pm 3.71)$ \\
\hline & Male & Target & $-6.33( \pm 5.18)$ & $-2.86( \pm 4.85)$ & $-0.17( \pm 4.99)$ \\
\hline & & Standard & $-1.40( \pm 3.67)$ & $1.35( \pm 2.49)$ & $1.44( \pm 2.25)$ \\
\hline \multirow[t]{4}{*}{ P300 } & Female & Target & $10.27( \pm 6.63)$ & $15.61( \pm 6.76)$ & $19.18( \pm 7.71)$ \\
\hline & & Standard & $1.34( \pm 3.38)$ & $3.63( \pm 3.78)$ & $5.12( \pm 3.50)$ \\
\hline & Male & Target & $5.99( \pm 5.35)$ & $10.00( \pm 4.09)$ & $12.03( \pm 3.87)$ \\
\hline & & Standard & $2.66( \pm 3.67)$ & $5.42( \pm 4.06)$ & $5.98( \pm 3.89)$ \\
\hline
\end{tabular}

statistics for the amplitude variations of the ERP peaks of males and females obtained in response to the target and standard stimuli from the three recording sites. Females had higher P300 response amplitudes than males. Target-evoked N200 and P300 peaks were higher in amplitude than standard-evoked ones. While target-evoked N100 was higher in males, target-evoked P300 was higher in females. For standard-evoked N100 and P300, gender effect shifted; standard evoked N100 was higher in females and standard evoked P300 was higher in males. Peak amplitudes changed according to recording site. P300 increased in amplitude towards the posterior recording sites and the negative peaks, (N100 and N200), increased in amplitude towards the anterior recording sites.

The effects of gender (female, male), stimulus type (target, standard) and recording site $(\mathrm{Fz}, \mathrm{Cz}, \mathrm{Pz})$ on amplitudes of the ERP peaks (N100, N200, P300) were tested using $2 \times 2 \times 3$ factorial design with repeated measures at the second and third factors. According to Mauchley's test, the data were not spherical. Taking the sample size into consideration, correction was performed using Huyn-Feldt epsilon in performing analysis of variance (ANOVA) (Vasey and Thayer, 1987). Table 2 presents a summary table of ANOVAs which were separately performed for each ERP peak (N100, N200, P300). Gender had a significant effect on P300 amplitude. Stimulus type had a significant effect on the N200 and P300 peaks. Recording site was found significant for all the studied ERP peaks. The interaction of gender and stimulus type was significant for $\mathrm{N} 100$ and P300. The interaction of stimulus type and recording site was significant for all peaks.

Fig. 3 displays the AFCs (second block of figures) for females (F) and males (M) which were obtained in response to target stimuli from the $\mathrm{Fz}, \mathrm{Cz}$ and $\mathrm{Pz}$ recording sites. Fig. 4 displays the findings obtained in response to the standard stimuli. The global representations that the AFCs provided suggested that the gamma selectivity was present in the
AFCs of both types of gender and of both stimulus types. Considering all experimental conditions, the frequency of the gamma response varied between 28 and $46 \mathrm{~Hz}$.

The third block in Figs. 3 and 4 displays the ERPs that were filtered in the gamma range (f-ERPs). The figures show that the time-locked gamma response occurred within a time window of $0-150 \mathrm{~ms}$ poststimulus in the f-ERPs of

Table 2

Summary tables for $2 \times 2 \times 3$ analysis of variance (ANOVA) with gender (Female, Male), stimulus type (Target, Standard) and recording site (Fz, Cz, $\mathrm{Pz}$ ) as predictive (Independent) variables and ERP peak amplitudes as predicted (Dependent) variables

\begin{tabular}{|c|c|c|c|c|}
\hline Sources of variance & Sum of squares & $d f$ & Mean square & $F$-values \\
\hline \multicolumn{5}{|l|}{ N100 Amplitude $(\mu V)$} \\
\hline Gender (A) & 47.33 & 1 & 47.33 & 0.84 \\
\hline Error & 2245.81 & 40 & 56.14 & \\
\hline Stimulus type (B) & 15.58 & 1 & 15.58 & 0.69 \\
\hline Error & 908.69 & 40 & 22.72 & \\
\hline Recording site (C) & 970.85 & 1 & 760.80 & $73.48^{* *}$ \\
\hline Error & 528.47 & 51 & 10.35 & \\
\hline $\mathrm{A} \times \mathrm{B}$ & 141.14 & 1 & 141.14 & $6.21^{*}$ \\
\hline Error & 908.69 & 40 & 22.72 & \\
\hline $\mathrm{A} \times \mathrm{C}$ & 2.82 & 1 & 2.21 & 0.21 \\
\hline Error & 528.47 & 51 & 10.35 & \\
\hline $\mathrm{B} \times \mathrm{C}$ & 22.51 & 1 & 17.11 & $5.52 *$ \\
\hline Error & 162.97 & 53 & 3.10 & \\
\hline $\mathrm{A} \times \mathrm{B} \times \mathrm{C}$ & 3.26 & 1 & 2.48 & 0.80 \\
\hline Error & 162.97 & 53 & 3.10 & \\
\hline \multicolumn{5}{|l|}{ N200 Amplitude $(\mu V)$} \\
\hline Gender (A) & 1.92 & 1 & 1.92 & 0.04 \\
\hline Error & 1693.15 & 40 & 42.33 & \\
\hline Stimulus type (B) & 313.79 & 1 & 313.79 & $5.91 *$ \\
\hline Error & 2124.75 & 40 & 53.12 & \\
\hline Recording site (C) & 1133.49 & 2 & 748.90 & $57.50 * * *$ \\
\hline Error & 788.52 & 61 & 13.02 & \\
\hline $\mathrm{A} \times \mathrm{B}$ & 114.70 & 1 & 114.70 & 2.16 \\
\hline Error & 2124.75 & 40 & 53.12 & \\
\hline $\mathrm{A} \times \mathrm{C}$ & 20.88 & 2 & 13.79 & 1.06 \\
\hline Error & 788.52 & 61 & 13.02 & \\
\hline $\mathrm{B} \times \mathrm{C}$ & 146.84 & 2 & 96.72 & $17.10^{* * *}$ \\
\hline Error & 343.57 & 61 & 5.66 & \\
\hline $\mathrm{A} \times \mathrm{B} \times \mathrm{C}$ & 0.65 & 2 & 0.43 & 0.07 \\
\hline Error & 343.57 & 61 & 5.66 & \\
\hline \multicolumn{5}{|l|}{ P300 Amplitude $(\mu V)$} \\
\hline Gender (A) & 297.48 & 1 & 297.48 & $4.66^{*}$ \\
\hline Error & 2554.61 & 40 & 63.86 & \\
\hline Stimulus type (B) & 4181.13 & 1 & 4181.13 & $67.77^{* * *}$ \\
\hline Error & 2467.67 & 40 & 61.69 & \\
\hline Recording site $(\mathrm{C})$ & 1312.86 & 2 & 873.94 & $75.78^{* * *}$ \\
\hline Error & 692.94 & 60 & 11.53 & \\
\hline $\mathrm{A} \times \mathrm{B}$ & 770.34 & 1 & 770.34 & $12.49 * * *$ \\
\hline Error & 2467.67 & 40 & 61.69 & \\
\hline $\mathrm{A} \times \mathrm{C}$ & 31.23 & 2 & 20.79 & 1.80 \\
\hline Error & 692.94 & 60 & 11.53 & \\
\hline $\mathrm{B} \times \mathrm{C}$ & 162.65 & 2 & 91.72 & $29.75^{* * *}$ \\
\hline Error & 218.72 & 71 & 3.08 & \\
\hline $\mathrm{A} \times \mathrm{B} \times \mathrm{C}$ & 16.45 & 2 & 9.28 & 3.01 \\
\hline Error & 218.72 & 71 & 3.08 & \\
\hline
\end{tabular}


both females and males in response to both the target and the standard stimuli at specifically the frontocentral recording sites. Data were analyzed using a $2 \times 2 \times 3$ ANOVA for the effect of gender (female, male), stimulus type (target, standard) and recording site $(\mathrm{Fz}, \mathrm{Cz}, \mathrm{Pz})$ with repeated

$$
\text { GAMMA (+) }
$$
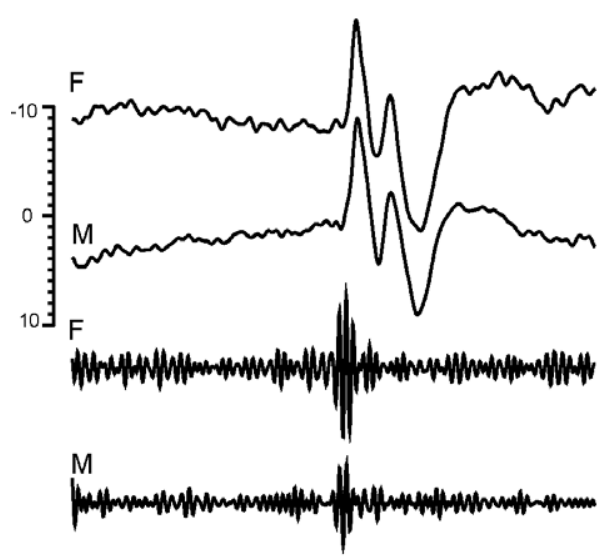

$\mathrm{Fz}$

ERP

measures at the second and third factors. According to Mauchley's test, the data were not spherical; accordingly, Huyn-Feldt was used as the epsilon value. The peak-topeak $\left(V_{\mathrm{p}-\mathrm{p}}\right)$ amplitude of the gamma response, which was measured between the most negative and most positive

$$
\text { GAMMA (-) }
$$

$\mathbf{z}$
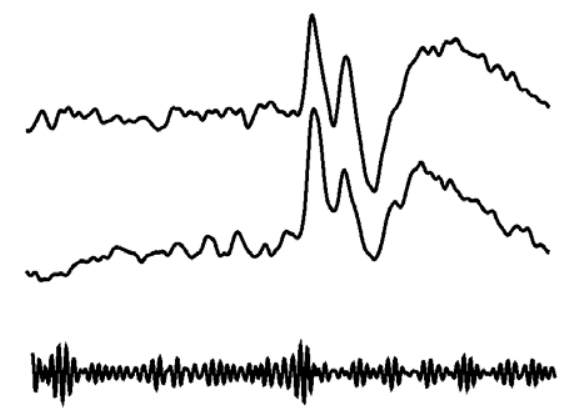

f-ERP

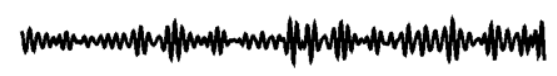

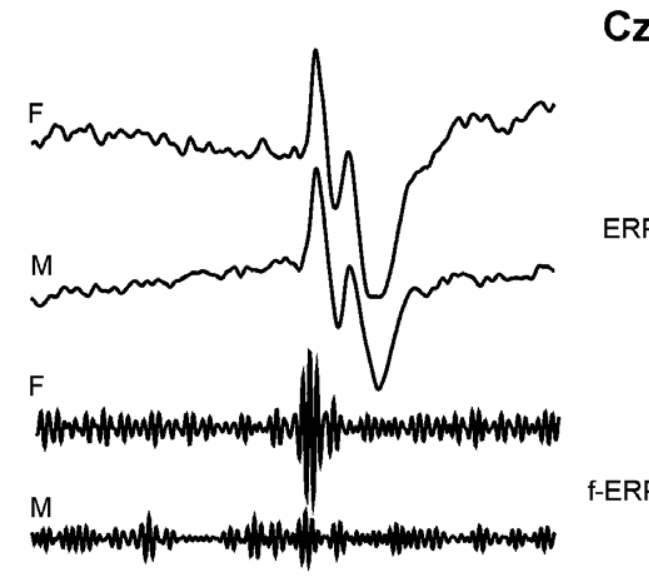

$\mathrm{Cz}$

RP
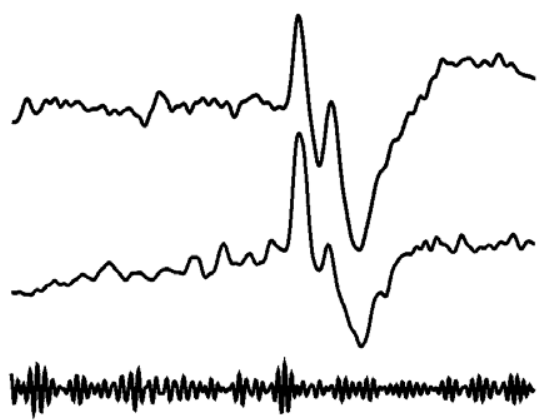

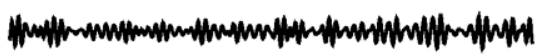

Pz
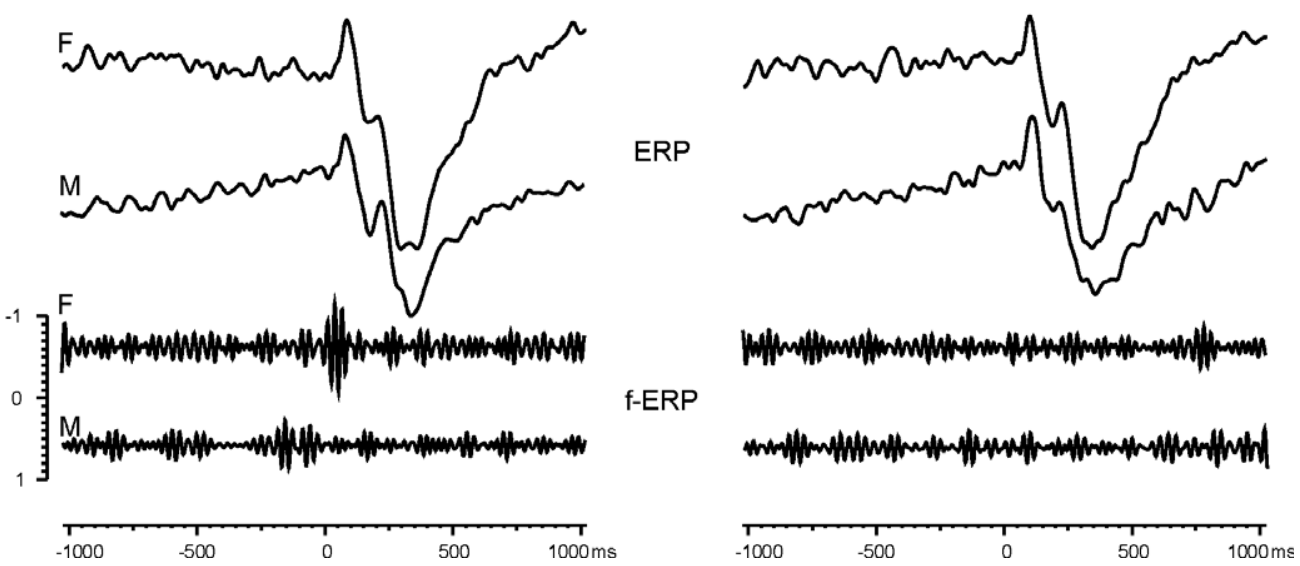

Fig. 5. The event-related potentials (ERPs) and filtered ERPs (f-ERPs) that were obtained for the target stimuli from the Fz, Cz and Pz recording sites in females (F) and males (M) with time-locked early gamma response, G+ (left column), and those without time-locked early gamma response, G- (right column). First four figures in each recording site: Event-related potential waveforms (ERPs). Second four figures in each recording site: ERPs filtered at the gamma range. Note that the $Y$-axis for ERPs and f-ERPs have scales proportional to the largest amplitude values in each representation. Stimulation onset was marked with " 0 ". 
points in the $0-150 \mathrm{~ms}$ time window, was not affected by stimulus type. Mean gamma response amplitudes of females were higher than males (for target stimuli means for females and males were, $1.49 \mu \mathrm{V}$ and $1.24 \mu \mathrm{V}$, respectively, at Fz; $1.65 \mu \mathrm{V}$ and $1.40 \mu \mathrm{V}$, respectively, at $\mathrm{Cz}$; and $1.27 \mu \mathrm{V}$ and $1.02 \mu \mathrm{V}$, respectively, at $\mathrm{Pz}$ ). However, this effect was not found significant. Recording site was found significant (Huyn-Feldt epsilon: $F_{(2,80)}=9.72, p=.001$ ). Post hoc analyses revealed that the significant effect originated from the difference between $\mathrm{Cz}$ and $\mathrm{Pz}$ recording sites (mean difference: .31, $p=.01$ ). The difference between $\mathrm{Fz}$ and $\mathrm{Cz}$, recording sites, on the other hand, was not significant. These findings showed that the early gamma response had a frontocentral distribution. None of the interaction effects were significant.

\subsection{Gender subtypes and individual differences in the time-locked gamma response}

\subsubsection{Findings from digital filtering}

The f-ERPs of each participant were studied for the presence of the early, time-locked gamma response. Classification of the data of 58 participants was performed by expert opinion and automated gamma detection technique. Two raters independently rated the data for the presence of the gamma response. There was $97 \%$ agreement between these raters. The data of only those participants for whom the detection technique and expert opinion showed $100 \%$ agreement were chosen for further analysis. Agreement was obtained on 22 participants in the $\mathrm{G}+$ group (37.93\%) and 20 participants in the $\mathrm{G}-$ group (34.48\%). Both detection approaches found the gamma response of 16 participants unclassifiable (27.59\%). Analyses of the present study were thus conducted on the data of a total of 42 participants; the group consisted of 22 females and 20 males (also see Section 2.1).

Fig. 5 displays the ERPs and the gamma responses (fERPs) of $\mathrm{G}+$ and $\mathrm{G}-$ females and males in response to the target stimuli at the $\mathrm{Fz}, \mathrm{Cz}$ and $\mathrm{Pz}$ recording sites. Since the gamma response was obtained from the frontocentral recording sites (Section 3.1, Figs. 3 and 4; also see Karakaş and Başar, 1998), data that were obtained from the $\mathrm{Fz}$ recording site were analyzed using $2 \times 2 \times 2$ ANOVA for the effect of gender (female, male), gamma status $(\mathrm{G}+$ and $\mathrm{G}-$ ) and stimulus type (target, standard) with repeated measures at the last factor. According to Mauchley's test, the data were not spherical; accordingly, Huyn-Feldt was used as the epsilon value. The $V_{\mathrm{p}-\mathrm{p}}$ amplitude of the gamma response was affected with gamma status $\left(F_{(1,38)}=16.23\right.$, $p=.0001)$; the response amplitude of the $\mathrm{G}^{+}$group was higher than of the $\mathrm{G}-$ group (mean amplitudes $1.69 \mu \mathrm{V}$ and $1.02 \mu \mathrm{V}$, respectively). When individual differences in the gamma response were not taken into account (Figs. 3 and 4), gender effect had not been found significant. However, when gamma status was analyzed using the $\mathrm{G}^{+}$and $\mathrm{G}-$ levels of the variable, ANOVA revealed a significant effect of gender $\left(F_{(1,38)}=5.64, p=.023\right)$. (The mean amplitude of females were $1.49 \mu \mathrm{V}$ and of males $1.37 \mu \mathrm{V}$.) ANOVA did not find a significant effect of stimulus type. The interaction effect between gender and gamma status was not found significant either. (In the $\mathrm{G}+$ group, mean amplitude of females was $1.97 \mu \mathrm{V}$ and of males $1.41 \mu \mathrm{V}$; in the $\mathrm{G}-$ group, the mean amplitude of females was $1.01 \mu \mathrm{V}$ and of males, $1.04 \mu \mathrm{V}$.)

Chi-square test for independent groups showed that the distribution of gender to gamma status was not significant $\left(\chi^{2}=.75, p>.05\right)$ (Table 3). This finding showed that $\mathrm{G}+$ and $\mathrm{G}-$ groups were homogeneously distributed over gender.

Fig. 5 shows that, in females, gamma status does not affect the ERP components. Even for target-evoked P300 for which females had a significantly higher amplitude than males (Tables 1 and 2, Fig. 3), $t$-test for independent groups showed that the difference between the $\mathrm{G}+$ and $\mathrm{G}-$ females (measured as $V_{\mathrm{p}-\mathrm{p}}$ between $\mathrm{N} 2$ and $\mathrm{P} 3$ in response to target stimuli at Fz) as nonsignificant. Males had higher amplitudes for target-evoked N100 and N200 (Tables 1 and 2, Fig. 3). In G- males, however, N200 lost its distinctiveness as a peak and appeared as a side peak on an extensive negativity that also included the $\mathrm{N} 100$. The $t$-test for independent groups showed that the difference between the $\mathrm{G}+$ and $\mathrm{G}-$ males (measured as $V_{\mathrm{p}-\mathrm{p}}$ between P2 and $\mathrm{N} 2$ in response to target stimuli at $\mathrm{Fz}$ ) as significant $(t=2.08, p=.05)$.

The effects of gender (female, male), stimulus type (target, standard) and recording site $(\mathrm{Fz}, \mathrm{Cz}, \mathrm{Pz})$ on amplitudes of the ERP peaks (N100, N200 and P300) were tested using only $\mathrm{G}+$ participants. A $2 \times 2 \times 3$ factorial design was used with repeated measures at the second and third factors. Data were not spherical, thus correction was performed using Huyn-Feldt epsilon in performing ANOVA. The results were similar to those obtained for the total sample that included $\mathrm{G}+$ and $\mathrm{G}-$ participants (Table 2). The only critical difference was obtained for P300. Gender had a significant effect on P300 in pooled data (Table 2); however, this effect was not significant when an ANOVA was conducted on only $\mathrm{G}+$ participants.

\subsubsection{Findings from TFCA}

In the present study, the gamma responses were also analyzed in the time-frequency plane using TFCA. Fig. 6 displays the application of TFCA to the averaged ERPs of the females (F) and males (M) in the $\mathrm{G}+$ and $\mathrm{G}-$ groups.

Table 3

$2 \times 2$ Chi-square test for the distribution of gender to gamma status $(p>.05)$

\begin{tabular}{lll}
\hline & Gamma present, $\mathrm{G}(+)$ & Gamma absent, G (-) \\
\hline Female & $n=11$ & $n=11$ \\
& $26.2 \%$ & $26.2 \%$ \\
Male & $n=11$ & $n=9$ \\
& $26.2 \%$ & $21.4 \%$ \\
\hline
\end{tabular}



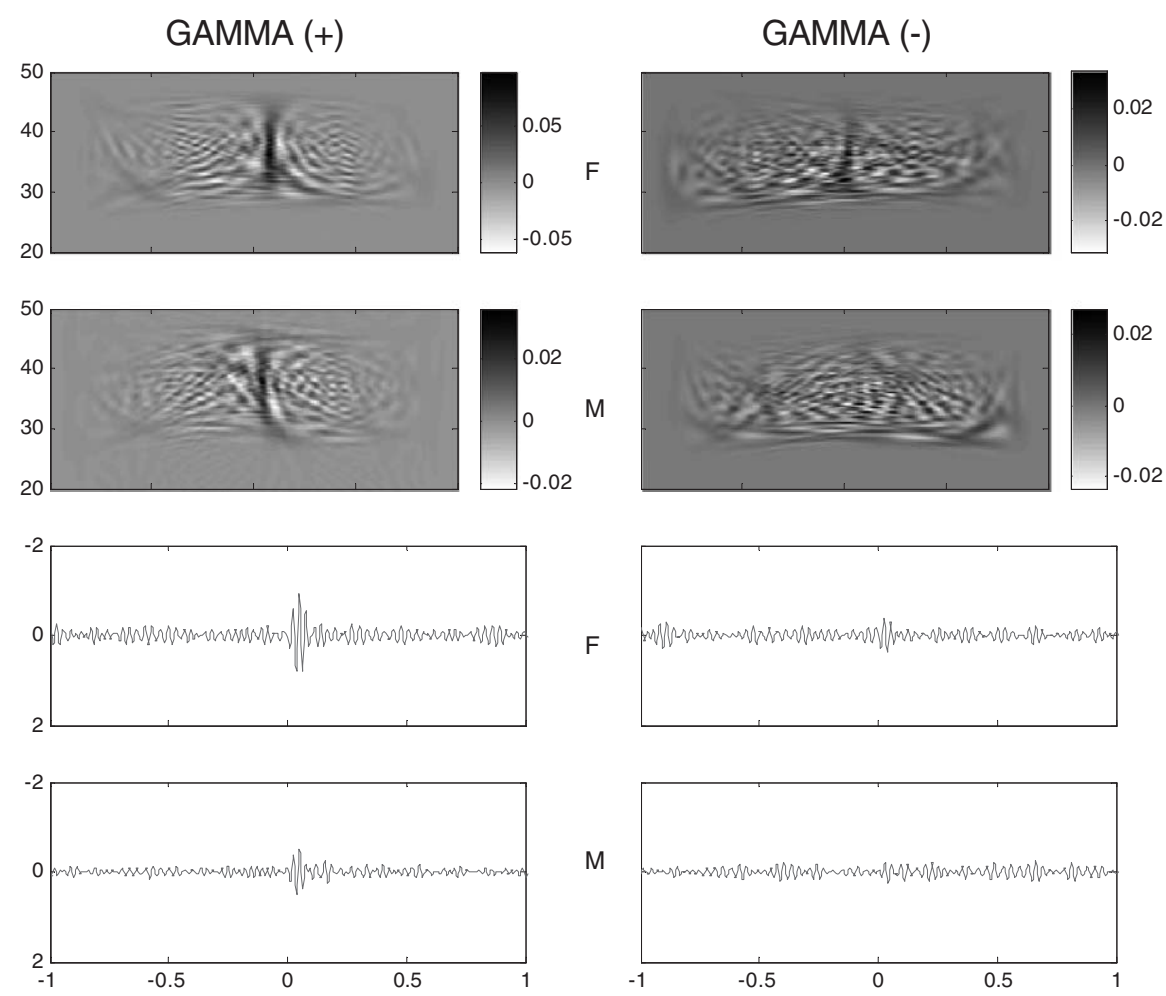

Fig. 6. TFCA analysis of the ERPs that were obtained for the target stimuli in females (F) and males (M) with time-locked early gamma response, G+ (left column), and those without time-locked early gamma response, G- (right column), from the Fz recording site. First four figures: Time-frequency representation produced by TFCA. Second four figures: Respective time-domain gamma components. For TFCA representations: $Y$-axes/left: frequency in Hz; $Y$-axes/right: amplitude; $X$-axis: time in seconds. Note that each TFCA representation has a scale that is proportional to the strength of its components. For timedomain gamma components: $Y$-axes/left: amplitude; $X$-axis: time in seconds. Stimulation onset was marked with "0".

The first block that consisted of four figures shows the localization of the gamma component in the timefrequency plane. The second block that also consisted of four figures shows the gamma components which were produced by TFCA in the time plane.

Both the time-frequency distribution of components and the time-domain activity that TFCA produced showed that the gamma activity occurred in both the prestimulus and poststimulus epochs. The left column in Fig. 6 shows the findings for the $\mathrm{G}+$ females and males. In the $\mathrm{G}+$ group, gamma activity was brought into resonance by stimulation. The stimulus-locked nature of the response is seen in TFCA as a high-energy component in the early time window (first two figures in the left column) and as a high amplitude component in the time-domain layout of the component (third and fourth figures in the left column). The gamma response occurred in a frequency range of $27.54 \mathrm{~Hz}$ and $42.46 \mathrm{~Hz}$.

The right column in Fig. 6 shows the findings for the Gfemales and males. In both the TFCA distribution (first two figures in the right column) and the time-domain layout (third and fourth figures in the right column), it is clearly seen that the component is not stimulus-locked. Unlike the $\mathrm{G}^{+}$group where the gamma response resonated upon stimulation, gamma in the $\mathrm{G}-$ group existed throughout the pre- and the poststimulus recording period with a comparable magnitude in a frequency range of $25.28 \mathrm{~Hz}$ and $37.19 \mathrm{~Hz}$. This gamma activity was not a response to the stimulus but a component that spontaneously occurred in the electroencephalogram (for a review, see Gottesmann, 1999).

The results of TFCA were statistically analyzed using two parameters of the gamma activity as dependent variables: maximum $V_{\mathrm{p}-\mathrm{p}}$ amplitude in the poststimulus early time window, ratio of the maximum $V_{\mathrm{p}-\mathrm{p}}$ amplitude in the poststimulus early time window to that in the prestimulus interval. Since there were two dependent variables, data were analyzed using $2 \times 2 \times 2$ multivariate analysis of variance (MANOVA) for the effect of gender (female, male), gamma status $(\mathrm{G}+$ and $\mathrm{G}-$ ) and stimulus type (target, standard) with repeated measures at the last factor. Data were derived from the Fz recording site.

As with the data on f-ERPs (Fig. 5), significant effects were obtained in the total model for gender (Wilks lambda: $F_{(2,75)}=3.58, p=.033$ ) and gamma status (Wilks lambda: $\left.F_{(2,75)}=11.55, p=.0001\right)$. Stimulus type and the interaction effects were not found significant. In MANOVA, each individual dependent variable was analyzed using a Bonferroni adjusted level of 0.25 . The two groups of gender differed in the maximum $V_{\mathrm{p}-\mathrm{p}}$ amplitude in the poststimulus early time window $\left(F_{(1,76)}=6.47, p=.013\right)$. The two groups of gamma status differed in both the maximum $V_{\mathrm{p}-\mathrm{p}}$ amplitude in the poststimulus early time window 
$\left(F_{(1,76)}=18.08, p=.0001\right)$ and in the ratio of the maximum $V_{\mathrm{p}-\mathrm{p}}$ amplitude in the poststimulus early time window to that in the prestimulus interval $\left(F_{(1,76)}=9.06, p=.004\right)$. Main effect of stimulus type and the interaction effects were not found significant for any of the dependent variables.

\section{Conclusions}

The present literature acknowledges the early, timelocked gamma response as a reliable neuroelectic phenomenon (Gurtubay et al., 2001; Herrmann and Mecklinger, 2001; Karakaş et al., 2001; Karakaş and Başar, 1998, 2004). Using time-domain (ERPs), frequency-domain (AFCs and f-ERPS) and time-frequency domain (TFCA) representations, the frontocentral gamma response was also demonstrated in the present study in response to the conditions of the auditory oddball paradigm (Figs. 3 and 4).

Individual differences in the gamma response have already been suggested in the previous literature (Jokeit and Makeig, 1994; Karakaş et al., 2001, 2003). There are a group of traits/characteristics in information processing such as field-dependence and handedness (Annett, 1970; Witkin et al., 1954). In terms of these traits/characteristics, there are two groups at either extreme: these would be field-dependence and field-independence or left handedness and right handedness. There is, however, a third group between the two extremes; this group shows varying amounts of the trait/ characteristics. Gamma status with $\mathrm{G}+$ and $\mathrm{G}-$ groups at the two extremes and the unclassifiable cases in between is one such trait/characteristics.

The two extremes, $\mathrm{G}+$ and $\mathrm{G}-$, were demonstrated in the present study with digital filtering (Fig. 5) and with TFCA (Fig. 6), a technique where neuroelectric components are simultaneously displayed in the time-frequency plane and where no assumption is made on system linearity and/or stationarity. Statistical analyses of the data obtained through digital filtering technique (maximum $V_{\mathrm{p}-\mathrm{p}}$ amplitude in the poststimulus early time window) and through TFCA technique (maximum $V_{\mathrm{p}-\mathrm{p}}$ amplitude in the poststimulus early time window, ratio of the maximum $V_{\mathrm{p}-\mathrm{p}}$ amplitude in the poststimulus early time window to that in the prestimulus interval) showed that gender as well as the gamma status affected the amplitude/energy of the gamma component, with higher values in females than in males and higher values in the $\mathrm{G}+$ group than in $\mathrm{G}-$ group.

However, the interaction between the gamma status and gender was found nonsignificant with both types of data. Lack of an interaction effect showed that gender is not a decisive factor in the gamma status. This conclusion was also reached through the chi-square test which showed that the gamma subtypes were homogeneously distributed over gender. Accordingly, the causal factor for the individual differences in the early, time-locked gamma response should be searched for not in gender differences but in other characteristics and/or processes. A genetic basis has been found of the beta frequency in human EEG (Porjesz et al., 2002). The investigation of a probable genetic basis of the time-locked gamma response should be among the prospective research areas in the field.

According to a large group of studies, the time-locked, early gamma response represents the early stages of information processing that include sensory and perceptual operations (Gurtubay et al., 2001; for a review, Karakaş et al., 2001; Karakaş and Başar, 1998, 2004). Karakaş et al. (2003) further found evidence for top-down influences that involve higher cognitive processes on the bottom-up, sensory-perceptual, early gamma response. The difference in the early gamma response was found to be correlated with neuropsychological test scores on attention, learning, shortterm memory and executive functions; $\mathrm{G}+$ and $\mathrm{G}-$ groups could be predicted from these scores with an overall success rate of $93.33 \%$. The present study found individual differences in gamma status which, however, did not depend on gender. The findings of the present study thus suggest that sensory-perceptual processing that the early time-locked gamma response represents (Karakaş and Başar, 1998) and the top-down influences on the early gamma response is not gender-specific (Karakaş et al., 2003). Such a conclusion and its implication should be extensively investigated, however, using standardized neuropsychological tests, complex research designs and advanced techniques of signal analysis.

\subsection{ERPs considered within a context of the gamma response}

The poststimulus $0-150 \mathrm{~ms}$ time window of the early gamma response includes the N100 and N200 ERP peaks. As a group of other studies also did (Gölgeli et al., 1999; Nagy et al., 2003), the present study found that amplitudes of N100 and, in part, N200 were higher in males (Table 1, Figs. 3 and 4). However, this relationship was complex. Male superiority was obtained in the target-evoked response (Table 1). Meanwhile, in the standard-evoked response, there was a female superiority. There was thus an interaction between gender and stimulus type which was found significant (Table 2).

When the sample was divided into $\mathrm{G}^{+}$and $\mathrm{G}-$ participants, the amplitudes of the negative peaks were not affected in females (Fig. 5). However, in G- males, the differentiation of the N200 peak became less evident and this difference was found significant. In G- males, N200 took place on an extended negativity that also included the N100 peak. Thus, if a sample consists of $\mathrm{G}-$ males, the result will be lower N200 in males, or conversely, higher N200 in females. The higher amplitude N200 in females is what another group of studies in fact found (Barrett and Fulfs, 1998; Hoffman and Polich, 1999; Kasai et al., 2002). The foregoing results on N200 suggest that the conflicting results in the literature may be due to experimental designs where variables (stimulus type, gamma status) that have the 
potential of interacting with the independent variable (gender) are not included in the experimental design.

As reported in the literature (Hoffman and Polich, 1999; Orozco and Ehlers, 1998; Osterhout et al., 1997), the present study found a significantly higher P300 amplitude in females (Tables 1 and 2). The posterior topography of the P300 is an indication that this is the P3b component, suggesting that females have a special position in attention and memory updating (Sutton et al., 1965; Polich and Kok, 1995). However, as in N200, there was a significant interaction effect on P300 such that there was a female superiority in target-evoked response amplitudes but a male superiority in standard-evoked response amplitudes (Tables 1 and 2, Figs. 3 and 4). Thus, higher amplitudes would be obtained in females only in response to the target stimuli.

Furthermore, the effect on P300 was obtained only when the sample included both $\mathrm{G}^{+}$and $\mathrm{G}-$ participants (Table 2). When analysis was conducted on only the $\mathrm{G}^{+}$ females, this effect was not found significant. As in $\mathrm{N} 200$, the foregoing results on P300 suggest that the conflicting results in the literature may be due to experimental designs where variables (stimulus type, gamma status) that have the potential of interacting with the independent variable (gender) are not included in the experimental design. Thus, when studies do not include these factors as variables but one study uses one level of the variable and the other one uses the other level, conflicting results would be found.

Shortly, also using techniques of time-frequency analysis, the present study showed that gender is not a factor in the individual differences concerning the status of the early gamma response. The amplitude variations in the ERP components (N100, N200, P300) can also not be explained solely on the basis of gender differences. Accordingly, even the earlier sensory-perceptual operations of information processing which the early gamma response, the N100 and the N200 ERP components represent, require an approach which would enable the discovery of the multifactorial pattern of influences.

\section{Acknowledgement}

This study was partially supported by Project Number TUBITAK-TBAG/CG-3.

\section{References}

Adrian, E.D., 1942. Olfactory reactions in the brain of the hedgehog. J. Physiol. 100, 459-473.

Annett, M., 1970. A classification of hand preference by association analysis. Br. J. Psychol. 61, 303-321.

Arıkan, O., Özdemir, A.K., Tüfekçi, İ., Çakmak, E.D., Karakaş, S., 2003. A new technique for joint time-frequency analysis of event-related signals of the brain: time-frequency component analyzer (TFCA). EEG Clin. Neurosci. Soc. (ECNS) 34 (3), 170.
Barrett, K.A., Fulfs, J.M., 1998. Effect of gender on the mismatch negativity auditory evoked potential. J. Am. Acad. Audiol. 9 (6), 444-451.

Başar, E., 1976. Biophysical and Physiological Systems Analysis. AddisonWesley, Amsterdam.

Başar, E., 1980. EEG-Brain Dynamics. Relation Between EEG and Brain Evoked Potentials. Elsevier/North-Holland, Amsterdam.

Başar, E., 1998. Brain Function and Oscillations: I. Brain Oscillations. Principles and Approaches, Springer-Verlag, Heidelberg, pp. 87-91, $293-327$.

Başar, E., 1999. Brain Function and Oscillations: II. Integrative Brain Function. Neurophysiology and Cognitive Processes, Springer-Verlag, Heidelberg, pp. 155-174, 331-435, 407-426.

Başar-Eroğlu, C., Strüber, D., Schürmann, M., Stadler, M., Başar, E., 1996. Gamma-band response in the brain: a short review of psychophysiological correlates and functional significance. Int. J. Psychophysiol. 24, $101-112$.

Berger, H., 1929. Uber des elektroenkephalogram. Arch. Psychiatr. Nervenkr. 87, 527-570.

Brandt, M.E., Jansen, B.H., 1991. The relationship between prestimulus alpha amplitude and visual evoked potential amplitude. Int. J. Neurosci. $61,261-268$.

Cohen, L., 1989. Time-frequency distributions: a review. Proc. IEEE 77 (7), 941-981.

Cohen, L., 1995. Time-Frequency Analysis. Prentice Hall, Englewood Cliffs, NJ.

Cook III, E.W., Miller, G.A., 1992. Digital filtering: background and tutorial for psychophysiologists. Psychophysiology 29, 350-367.

Dawson, G.D., 1954. A summation technique for the detection of small evoked potentials. Electroencephalogr. Clin. Neurophysiol. 6, $153-154$.

Farwell, L.A., Martinerie, J.M., Bashore, T.R., Rapp, P.E., Goddard, P.H., 1993. Optimal digital filters for long-latency components of the eventrelated brain potential. Psychophysiology 30, 306-315.

Galambos, R., 1992. A comparison of certain gamma band $(40 \mathrm{~Hz})$ brain rhythms in cat and man. In: Başar, E., Bullock, T.H. (Eds.), Induced Rhythms in the Brain. Birkhäuser, Boston.

Gölgeli, A., Süer, C., Özesmi, Ç., Dolu, N., Aşçığlu, M., Şahin, O., 1999. The effect of sex differences on event-related potentials in young adults. Int. J. Neurosci. 99 (1-4), 69-77.

Gottesmann, C., 1999. Neurophysiological support of consciousness during waking and sleep. Prog. Neurobiol. 59, 469-508.

Gurtubay, A.M., Labura, A., Malanda, A., Iriarte, J., Artieda, J., 2001. Gamma band activity in an auditory oddball paradigm studied with the wavelet transform. Clin. Neurophysiol. 112, 1219-1228.

Herrmann, C.S., Mecklinger, A., 2001. Gamma activity in human EEG is related to high-speed memory comparisons during object selective attention. Vis. Cogn. 8 (3-5), 593-608.

Hoffman, L.D., Polich, J., 1999. P300, handedness, and corpus callosal size: gender, modality, and task. Int. J. Psychophysiol. 31 (2), $163-174$.

Jervis, B.W., Nichols, M.J., Johnson, T.E., Allen, E., Hudson, N.R., 1983. A fundamental investigation of the composition of auditory evoked potentials. IEEE T. Bio-Med. Eng. BME 30, 43-49.

Jokeit, H., Makeig, S., 1994. Different event-related patterns of gammaband power in brain waves of fast- and slow-reacting subjects. Proc. Natl. Acad. Sci. U. S. A. 91 (14), 6339-6343.

Karakaş, S., Başar, E., 1998. Early gamma response is sensory in origin: a conclusion based on cross-comparison of results from multiple experimental paradigms. Int. J. Psychophysiol. 31 (1), 13-31.

Karakaş, S., Başar, E., 2004. Oscillatory responses of the brain and their cognitive correlates. In: Adelman, G., Smith, B.H. (Eds.), Encyclopedia of Neuroscience, 3rd edn. Elsevier, San Diego, CA.

Karakaş, S., Erzengin, Ö.U., Başar, E., 2000a. A new strategy involving multiple cognitive paradigms demonstrates that ERP components are determined by the superposition of oscillatory responses. Clin. Neurophysiol. 111, 1719-1732. 
Karakaş, S., Erzengin, Ö.U., Başar, E., 2000b. The genesis of human eventrelated responses explained through the theory of oscillatory neural assemblies. Neurosci. Lett. 285, 45-48.

Karakaş, S., Başar-Eroğlu, C., Özesmi, Ç., Kafadar, H., Erzengin, Ö.U., 2001. Gamma response of the brain: a multifunctional oscillation that represents a bottom-up with top-down processing. Int. J. Psychophysiol. $39(2-3), 137-150$

Karakaş, S., Bekçi, B., Erzengin, Ö.U., 2003. Early gamma response in human neuroelectric activity is correlated with neuropsychological test scores. Neurosci. Lett. 340, 37-40.

Kasai, K., Nakagome, K., Iwanami, A., Fukuda, M., Itoh, K., Koshida, I., Kato, N., 2002. No effect of gender on tonal and phonetic mismatch negativity in normal adults assessed by a high-resolution EEG recording. Brain Res. Cogn. Brain Res. 13 (3), 305-312.

Kolb, B., Whishaw, I.Q., 1996. Human Neuropsychology, 4th edn. W.H. Freeman, New York.

Kolev, V., Yordanova, J., 1997. Analysis of phase-locking is informative for studying event-related EEG activity. Biol. Cybern. 96, 229-235.

Maccoby, E., Jacklin, C.N., 1974. The Psychology of Sex Differences. Stanford Univ. Pr., Stanford.

Naatanen, R., 1990. The role of attention in auditory information processing as revealed by event-related potentials and other brain measures of cognitive function. Behav. Brain Sci. 13 (2), 201-288.

Naatanen, R., 1992. Attention and Brain Function. Lawrence Erlbaum Assoc., London.

Naatanen, R., Picton, T., 1986. N2 and automatic versus controlled processes. In: McCallum, W.C., Zappoli, R., Denoth, I. (Eds.), Cerebral Psychophysiology. Studies at Event-Related Potentials (EEG Suppl. 38). Elsevier, North-Holland.

Nagy, E., Potts, G.F., Loveland, K.A., 2003. Sex-related ERP differences in deviance detection. Int. J. Psychophysiol. 48 (3), 285-292.

Orozco, S., Ehlers, C.L., 1998. Gender differences in electrophysiological responses to facial stimuli. Biol. Psychiatry 44 (4), 281-289.

Osterhout, L., Bersick, M., McLaughlin, J., 1997. Brain potentials reflect violations of gender stereotypes. Mem. Cogn. 25 (3), 273-285.

Ozaktas, H.M., Arıkan, O., Kutay, M.A., Bozdagi, G., 1996. Digital computation of the fractional Fourier transform. IEEE Trans. Signal Process. 44, 2141-2150.

Özdemir, A.K., Arıkan, O., 2000. A high-resolution time frequency representation with significantly reduced cross-terms. Proc. IEEE Int. Conf. Acoust. Speech Signal Proc. 2, 693-696.

Özdemir, A.K., Arıkan, O., 2001. Efficient computation of the ambiguity function and Wigner distribution on arbitrary line segments. IEEE Trans. Signal Process. 49, 381-393.
Özdemir, A.K., Durak, L., Arıkan, O., 2001. High-resolution timefrequency analysis based on fractional domain warping. Proc. IEEE Int. Conf. Acoust. Speech Signal Proc. 6, 3553-3556.

Özdemir, A.K., Karakaş, S., Çakmak, E.D., Tüfekçi, D.İ., Arikan, O., 2005. Timefrequency component analyzer and its application to brain oscillatory activity. J. Neurosci. Methods 145, 107-125.

Parvin, C., Torres, F., Johnson, E., 1980. Synchronization of single evoked response components: estimation and interrelation of reproducibility measures. In: Pfurtscheller, G., Busser, P., Lopes da Silva, F., Petsche, H. (Eds.), Rhythmic EEG Activities and Cortical Functioning. Elsevier, Amsterdam.

Polich, J., Kok, A., 1995. Cognitive and biological determinants of P300: an integrative review. Biol. Psychol. 41 (2), 103-146.

Porjesz, B., Almasy, L., Edenberg, H., Wang, K., Chorlian, D.B., Foroud, D., et al., 2002. Linkage disequilibrium between the beta frequency of the human EEG and a GABA (A) receptor gene locus. Proc. Natl. Acad. Sci. 99, 3729-3733.

Röschke, J., Aldenhoff, J.B., 1991. Excitability and susceptibility of the brain's electrical activity during sleep: an analysis of late components of AEP and VEPs. Int. J. Neurosci. 56, 255-272.

Röschke, J., Mann, K., Riemann, D., Frank, C., Fell, J., 1995. Sequential analysis of the brain's transfer properties during consecutive REM episodes. Electroencephalogr. Clin. Neurophysiol. 96, 390-397.

Röschke, J., Prentice-Cuntz, T., Wagner, P., Mann, K., Frank, C., 1996. Amplitude frequency characteristics of evoked potentials during sleep: an analysis of brain's transfer properties in depression. Biol. Psychiatry $40,736-743$

Solodovnikov, V.V., 1960. Introduction to the Statistical Dynamics of Automatic Control Systems. Dover, New York.

Sutton, S., Braren, M., Zubin, J., John, E.R., 1965. Evoked potential correlates of stimulus uncertainty. Science 150, 1187-1188.

Ungan, P., Başar, E., 1976. Comparison of Wiener filtering and selective averaging of evoked potentials. Electroencephalogr. Clin. Neurophysiol. $40,516-520$

Vasey, M.W., Thayer, J.F., 1987. The continuing problem of false positives in a repeated measures ANOVA in psychophysiology: a multivariate solution. Psychophysiology 24 (4), 479-486.

Vincent, L., Soille, P., 1991. Watersheds in digital spaces: an efficient algorithm based on immersion simulations. IEEE Trans. Pattern Anal. Mach. Intell. 13 (6), 583-598.

Witkin, H.A., Lewis, H.B., Hertzman, M., Machover, K., Meissner, P., Wapner, S., 1954. Personality Through Perception. Harper, New York. 